\title{
Widening the Disciplinary Scope of eParticipation. Reflections after a Research on Tourism and Cultural Heritage
}

\author{
Francesca Ricciardi ${ }^{1}$ and Patrizia Lombardi ${ }^{2}$ \\ ${ }^{1}$ Università Cattolica di Milano, Italy \\ ${ }^{2}$ Politecnico di Torino, Italy \\ Francesca.ricciardi@unicatt.it, patrizia.lombardi@polito.it
}

\begin{abstract}
Cultural Heritage and Tourism Development may be strong driving factors for local policies and may have great importance in strategic decision making at territorial level; then, they may be important subjects for eParticipation studies. But this paper demonstrates, through a literature review, that today's disciplinary shape of eParticipation as a research field is not suitable to effectively investigate participatory processes related to Tourism and Cultural Heritage. Then, by presenting a field research, which took place in the Italian city of Genoa, and by confronting its outcomes with some most widespread disciplinary eParticipation underpinnings, the paper seeks to identify some areas where a widened disciplinary scope is particularly needed. Finally, we propose a new disciplinary framework, suitable to address also Cultural Heritage and Tourism Development eParticipation processes.
\end{abstract}

Keywords: eParticipation, participatory planning, tourism, cultural heritage, ICT.

\section{Introduction}

"eParticipation involves the extension and transformation of participation in societal democratic and consultative processes mediated by information and communication technologies (ICT), primarily the Internet. (...) It aims to support active citizenship with the latest technology developments, increasing access to and availability of participation in order to promote fair and efficient society and government". [1] Theoretical discussions involving participation span a large range of disciplines (for example, participatory management, or participatory design); but eParticipation normally focuses on participatory processes connected with political or public interest decision-making, and is consequently strictly connected to sister disciplines such as eGovernment [2] and eDemocracy [3] [4].

On the other side, eParticipation is a young disciplinary field, whose boundaries are still under discussion and whose theoretical underpinnings are still under elaboration [1]. Many issues related to public interest and political and administrative decision-making are still scarcely investigated in eParticipation studies. 
For example, cultural heritage and tourism development may be unique driving factors for local policies and may have great importance in strategic decision making at territorial level [5]; then, they may be important subjects for eParticipation studies. This paper demonstrates, through a literature review, that in today's disciplinary scenario eParticipation researches involving tourism and cultural heritage management processes are very few, and scarcely supported by methodological and theoretical frameworks. The method and the outcomes of this literature review are presented in Paragraph 2.

Paragraph 3 will present a three-years field research (in which one of the authors of this paper was involved) focused on developing an e-participatory / e-governance model for cultural tourism development of the city of Genoa, Italy.

Then, paragraph 4 will seek to use the experience and the outcomes of Genoa field research, along with the outcomes of literature search, to identify some areas of widening and improvement of the eParticipation disciplinary framework.

Finally, Paragraph 5 will propose a new disciplinary framework, in which the areas of needed widening and improvement identified are addressed. In particular, this study will suggest a description of possible eParticipation (i) Actors, (ii) Activities, and (iii) Effects, aimed at classifying, through Concept Matrixes suitable also for evaluation purposes, eParticipation studies and experiences, included those which are related to Cultural Heritage and Tourism management.

In the Conclusions, the outcomes of our theory-building effort will be synthesized, and some areas of improvement and further research will be identified.

\section{Tourism and Cultural Heritage Management Issues within E-Participation Literature}

Tourism and Cultural Heritage management almost always involves planning activity at city, regional and/or national level; it often implies Public Authorities (P.A.) decision-making, government processes and political commitment [6].

This makes Tourism and Cultural Heritage $(\mathrm{CH})$ management a potentially fertile field for e-participation.

For example, Go, Lee and Russo [7] remark the possible positive impact of ICTs when both citizens and (cultural) tourists actively participate in policy and decision making processes. Innes and Bohr [8] highlight the importance of involving local communities in cultural tourism decision making, to take into account the complexity of concrete local culture and local problems, and to keep development processes well balanced.

Sigala and Leslie [9] note that transforming a site into a tourism destination may have negative socio-cultural consequences, and identify e-participation as a possible tool to face the problem.

Nevertheless, e-participation is very rarely applied in tourism and cultural heritage actual management and decision-making processes [10]; moreover, the presence of eparticipation in tourism/ $\mathrm{CH}$ literature is poor and often limited to generic complaints, ideas and suggestions, as we will seek to demonstrate below. 
To examine the role of Cultural Heritage and Tourism Development issues in today's eParticipation journal publications, a literature search was conducted in February 2010.

The following on-line Databases were selected as particularly important for eparticipation issues: Econlit, E-Journals, Business Source Premier.

Four searches were conducted in this Databases, through the EBSCO search engine.

The first query asked to search writings including the words "e-participation" (or "eParticipation") and "tourism" in the Abstract. The result was 0: no writing included those two terms in the Abstract.

A second query asked to find writings including "participation" (without "e-") and "tourism" in the Abstract. 134 writings were found, many of which were not relevant in that the term "participation" was not related to the concepts of "discussion" and "decision making" (e.g. "participation in revenues"). 17 writings included just generic complaints (e.g. "local community participation to planning and decision making should be enhanced"). Four writings were actually focused on participatory and collaborative planning in Tourism/Cultural Heritage management processes. Among these four writings, two included somehow generalizable hypotheses about success factors in participatory processes: Bahaire and Elliott-White [11] interestingly highlight the conflicts and contradictions, in tourism planning and development, between public-private sector partnerships (based on elite groups and entrepreneurial city management) and public participation. Yuksel [12] notes, after a statistical analysis, that along with other structural and cultural factors, residents' perceptions of the intensity of clientelist relations between the local authority and other stakeholders may significantly decrease active participation of citizens in developmental issues, and in tourism planning particularly.

In no writing, among the 134 provided by the search system, ICTs were identified as a driver or a significant factor for enhancing participation in tourism $/ \mathrm{CH}$ management and planning.

A third search was launched, asking the system to find writings including "egovernment" and "tourism" in the Abstract. The system found 7 writings, but none of them focused on the issue of using ICTs to promote public participation in discussion and decision-making on tourism development and $\mathrm{CH}$ management. The 7 writings focused on top-down classical management issues (and on tourism promotion above all) without investigating if, and under what conditions, ICT tools could be also used for bottom-up participation.

A fourth search was launched, using "e-governance" and "tourism" as keywords. Only one writing was found [13]. In this paper, the authors present an e-governance model developed for cultural tourism in the Italian city of Genoa. The purpose is to involve the stakeholders (citizens and tourists included) in discussions and decisions about on-line promotion and communication of the city's cultural heritage and tourism attractions. In this project, thus, people are involved in a precise, limited decision-making process, which does not imply more complex processes of city planning or participatory design: the aim is to provide, with the aid of participants, more effective e-services for tourists.

This field research will be one main basis of our theoretical proposal, and will be more thoroughly described in the following paragraphs. 
To complete this survey on the role of $\mathrm{CH} /$ tourism related issues in e-participation studies, we have taken into consideration the systematic literature review conducted in 2008 by Sæbø,, Rose and Skiftenes Flak [1], aimed at characterizing e-participation as a research field.

The authors, after analyzing 131 writings deemed highly relevant, among the 651 yielded by the keyword search, describe the disciplinary boundaries and key concepts of eParticipation, which can be drawn from literature. Firstly, the authors identify what are, according to literature, eParticipation Actors, dividing them into 4 groups: citizens, politicians, government institutions, voluntary organizations. Secondly, the authors list eParticipation Activities described in literature: eVoting, online political discourse, online decision making, eActivism, eConsultation, eCampaigning, ePetitoning. The authors explicitly say that in their model "pure information exchange activities lie outside the scope of eParticipation because there is no participative element" (p. 410).

Then, the authors describe the contextual factors influencing eParticipation identified in literature, namely: information availability, net infrastructures, underlying technologies (i.e. HW/SW), accessibility, policy and legal issues, governmental organization. In Sæbø,, Rose and Skiftenes Flak's work, more general factors influencing participation, such as trust in government or conflicting interests, are not mentioned, letting it be understood that the analyzed 131 writings had not investigated such issues.

Finally, the authors describe what are, according to the literature they analyzed, eParticipation effects, and possible eParticipation evaluation metrics. The authors complain that the analyzed literature is quite poor as for these issues, and in fact both the list of eParticipation effects (civic engagement; deliberative and democratic effects) and of eParticipation evaluation metrics (quantity of participation; demographic of participants; tone and style in online activities) appear, even at a first glance, generic and unsatisfactory.

\section{The Genoa Field Research}

The City of Genoa is an internationally renowned centre of culture and heritage. Its reputation grew in 2004 when it was nominated 'The European Capital of Culture'. Amongst its many cultural sites and attractions, of most interest to the visitors are the Unesco word heritage site Palazzi dei Rolli, the City Museum, Strada Nuova, Palazzo Rosso, Ducale Palace, Luzzati Museum, Spinola Palace, Sea Museum (Galata), Genoa Aquarium, Luzzati Museum, Spinola Palace, and the National Gallery. The city has recently embraced a strategic policy to transform the port, culture, and tourism as main vehicles of economic revival based on social inclusion, urban integration, and sustainable development, with ICT playing a major role. A recent study conducted by a number of researchers of the ISAAC project [14] found that the city's main web portal is a true gateway to information on tourism attractions, local museums, historic buildings, urban squares, and cultural events. Yet, the content is developed and presented by the city tourism authorities only and there is no communication with the users as regards its type, quality, user preferences, and so forth. At the same time, local heritage providers use only limited digital media in the 
promotion of their attractions. To improve electronic services and widen access and participation in cultural heritage development, the city of Genoa has chosen to participate in the EU FP6 Project ISAAC "Integrated e-Services for Advanced Access to Heritage in Cultural Tourist Destinations" and to develop the e-governance system in close collaboration with 'Fondazione Eni Enrico Mattei' [15].

From April to October 2007, four focus groups involving tourist, residents, local service providers and external service providers separately, were administered with thirty-seven participants aiming at (i) exploring their local heritage perceptions, (ii) selecting the most relevant heritage sites for Genoa, and (iii) identifying the most appropriate e-services for each of the selected sites. An on-line debate continued among the participants remotely in the following three weeks. The second phase consisted of an on-site focus group session held in February 2008, involving fifteen tourists, residents and service providers together that aimed to identify the priority of e-services defined in the first phase.

The e-governance website (www.isaac-genovaculture.eu) was structured in three main sections, each with a different function: information, communication and participation. The information section aimed at providing information and sensitize people about local cultural heritage resources. Here users are passive learners about local heritage and the available opportunities. The communication section aimed at creating a virtual public space for exchanging general opinions and ideas about cultural heritage among the citizens. Here, the users become authors of the web content. Finally, the participation section aimed at creating a more advanced level of interaction between decision makers and users with the latter getting involved in the decision-making process.

The first round of the face-to-face focus groups provided important insights about how users perceive and value local heritage in Genoa and their differences. Local and external services providers, for example, identified some 36 and 30 cultural heritage sites respectively, out of the 58 sites chosen by all participants. This shows that service providers are much more aware of local cultural heritage offers than residents and tourists, suggesting insufficient 'access' to cultural heritage supply by residents and tourists in the local tourism promotional activities.

Furthermore, when each user group was asked to associate added value to the territory - historical, cultural, tourist, social, environmental and emotional - by the selected cultural sites, service providers seemed more prone to capture cultural and historical values while tourists and residents placed more attention on social, environmental and emotional values. Furthermore, tourists in general emphasized more environmental values as compared to the residents, which shows that the latter associate sites with experiences, hence territorial identity and value of place have a stronger relevance to the visitors than to local residents. So the issue of access to heritage for the local residents comes out again strong. Interestingly enough, some of the participants attributed rather unexpected and 'unusual' values to sites, like the 'Ancient Port', 'Aquarium' and the 'Lanterna', which reinforces the notion that cultural heritage users have subjective and changeable perceptions of it, therefore, its ongoing monitoring becomes essential to ensure sustainable management of the sector. For further details, see [13] and [15]. 


\section{Challenges to the Disciplinary Boundaries}

The Genoa field research, when compared with the disciplinary shape of eParticipation as described by [1], reveals several aspects where a widening of disciplinary scope and frameworks is needed.

In fact, Sæbø, Rose and Skiftenes Flak's list of eParticipation actors (Citizens, Politicians, Government Institutions, and Voluntary Organizations) does not include several actors that were actually crucial in Genoa research, i.e. Tourists (who may not be Citizens of the country/region/city where decision making takes place), Researchers, Businesses and Business Groups. Moreover, other potentially important actors of e-participation could be: Lobbies/Groups of Interest, Professionals involved in planning / design activities, Press and Journalists (many e-consultation activities, for example, are organized by the newspapers' web sites today). Important contradictions and conflicts may raise between these diverse Actors, and these contradictions and conflicts should be considered an important subject of studies in research focused on participatory activities, be they supported by new technologies or not.

Moreover, another important outcome of the Genoa experience is that eParticipation activities demonstrated themselves as not "spontaneous": even for the "mere" content management processes, they require efforts, which are often overlooked or underestimated. Thus, eParticipation needs the motivated commitment of at least one Actor; when the Actor who took the initiative loses its interest in the eParticipation acivity (in the Genoa case, when ISAAC group ended its research) the activity is likely to be abandoned by all the other Actors.

On the other side, Sæbø,, Rose and Skiftenes Flak's list of eParticipation activites, though rich and articulated, does not include discussion and knowledge sharing [1]. Sæbø,, Rose and Skiftenes Flak, in fact, think that information availability is part of the context, i.e. a prerequisite of eParticipation, just like net infrastructures or software applications. But the field experience of Genoa, and in particular the potentialities of ISAAC platform, showed that it is often impossible, in practice, to separate the moment of making information available from the moment of participation: information is often created during discussion, and then information sharing has revealed, during Genoa field research, as a possible eParticipation activity in itself.

The Genoa experience allowed also a rethinking of what could or should be the eParticipation effects, with particular regard to increased awareness of actors, increased territorial value, enhanced civil rights, improved territorial services. The enlarged lists of eParticipation Actors and eParticipation Activities that we propose will be more thoroughly presented in the next paragraph, along with a description of the main eParticipation effects we identified.

\section{A Renewed Disciplinary Framework}

On the basis of the field research experience, of our literature analysis and of our experience as researchers and as practitioners, we propose a new draft of disciplinary 
framework, with a widened scope, including 3 categories of entities: eParticipation Actors, eParticipation Activities, eParticipation Effects.

Whilst for the first two categories our list stems from [1], just with several added Actors and Activities that Sæbø, Rose and Skiftenes Flak did not mention, for the third category we propose a list organized in a completely different way.

eParticipation possible Actors:

1. Citizens

2. Politicians

3. Governmental Institutions

4. Voluntary Organizations

5. Users and Customers of the Territorial System (e.g. Tourists)

6. Businesses and Business Groups

7. Lobbies and Groups of Interests

8. Professionals involved in Territorial Planning activities

9. Researchers and scholars

10. Press and Journalists.

eParticipation possible Activities:

a) Discussion and knowledge sharing (aimed at or related to civil participation in public-interest decision making)

b) eVoting

c) online political discourse

d) online decision making

e) eActivism

f) eConsultation

g) eCampaigning

h) ePetitoning

eParticipation expected Effects:

I Improved Civic Awareness

II Improved Civic Engagement

III Enhanced Civil Rights

IV Increased Territorial Value

V Improved Territorial Services

The category eParticipation (expected) Effects deserves some more thorough comments. We propose to include Civic Awareness in this category because participatory activity, independently from actual decision-making, implies discussion, knowledge sharing and consequently a growth in awareness on the part of (ideally) all the Actors. For example, public officers may become more aware of concrete implications of adopted policies; citizens may want to monitor the outcomes of decision-making processes they (or their representatives) were involved in. It is important to note that the mere existence and use of e-participation tools does not imply, in itself, improved civic awareness: for example, [16] asserts that simplistic and distorted political information easily spreads throughout the web; and this phenomenon, far from enhancing civic awareness, tends to undermine it. 
Engagement, on the other side, was included in Sæbø, Rose and Skiftenes Flak's framework. Improved civic engagement on the part of Actors may be one possible effect of eParticipation. But also this concept is problematic, because whilst many authors optimistically think that new technology cam be powerful triggers to enhance civic engagement (e.g. [17] [18]), many other authors highlight that there is little correlation between the increasing facilitations provided by e-tools and actual enhancing in civic engagement [19] [20] [21].

Civil Rights, which may or should be enhanced by successful eParticipation activities, could be (but are not limited to): protection from discriminations; equal access to care, education and culture; inclusion and participation in civil society and politics; freedom of expression and communication.

Whilst eParticipation Effects I, II and III mainly involve eParticipation Actors, by identifying eParticipation Effects IV and V we have concentrated on what could or should be the expected outcomes of eParticipation from a general point of view. Successful eParticipation activities, in fact, being aimed at improving decisionmaking processes, should result in concrete improvements in the real world, on a territorial basis. Improvements due to good decision-making at political and administrative level may be very numerous and different in nature; here, we have concentrated on two aspects, which of course are not exhaustive, but are representative of the issues raised by the Genoa field research.

eParticipation effect IV refers to the fact that good decision-making should result in measurable improvement of territorial assets. Such improvement could be effectively described and measured using the concept of Territorial Value. Literature on environmental economics has highlighted the ability of $\mathrm{CH}$ to produce "intrinsic" and "extrinsic" values. The concept of "territorial value" is one of the most important in this field [26]. It refers to the tangible and intangible linkages and relationships between Cultural Heritage and the (urban) context. This value is very important for tourism sector as it refers to public consciousness and perception of values: that's why we propose to include it in the Framework.

Also eParticipation Effect V refers to an effect of participatory activity that may involve the whole socio-territorial context, and not only eParticipation Actors. The expression Improved Territorial Services spans a very large range of possible good (e)Participation effects. For example, the Genoa field research was aimed at designing an on-line portal included several e-services for tourists. Moreover, the participatory activity provided information on how many real-world services, such as bus lines, could be re-organized to better meet the Actors' needs.

This framework allows to describe each specific eParticipation initiative with specific concept matrixes. For example, the Genoa project could be synthetically represented as follows:

For each activated crossing between eParticipation Actors and eParticipation Activities, expected eParticipation Effects can be identified: for example, the participation into the activity of eConsultation, on the part of Tourists (as Users/Customers of the territorial system) was expected to result in improved webbased services for Genoa tourism promotion. 
Table 1. The classification of Genoa field research into the eParticipation Framework

\begin{tabular}{|c|c|c|c|c|c|c|c|c|}
\hline $\begin{array}{l}\qquad \text { Activities } \rightarrow \\
\text { Actors } \downarrow\end{array}$ & 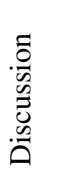 & 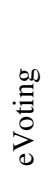 & 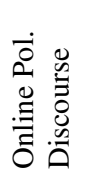 & 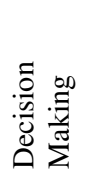 & 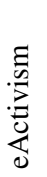 & 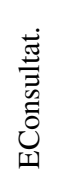 & 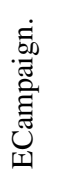 & 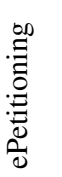 \\
\hline Citizens & $\mathrm{x}$ & & & $\mathrm{x}$ & & $\mathrm{x}$ & & \\
\hline Politicians & & & & & & & \multirow{3}{*}{\multicolumn{2}{|c|}{$\begin{array}{l}\text { Improved } \\
\text { e-services } \\
\text { (Tourism } \\
\text { Portal) }\end{array}$}} \\
\hline $\begin{array}{l}\text { Governmental } \\
\text { Institutions }\end{array}$ & $\mathrm{x}$ & & & $\mathrm{x}$ & & & & \\
\hline $\begin{array}{l}\text { Voluntary } \\
\text { Oganizations }\end{array}$ & & & & & & & & \\
\hline $\begin{array}{l}\text { Users and } \\
\text { Customers of the } \\
\text { Territorial System }\end{array}$ & $\mathrm{x}$ & & & $\mathrm{x}$ & & $\mathrm{X}$ & & \\
\hline $\begin{array}{l}\text { Businesses and } \\
\text { Business Groups }\end{array}$ & $\mathrm{x}$ & & & $\mathrm{x}$ & & $\mathrm{x}$ & & \\
\hline $\begin{array}{l}\text { Lobbies and } \\
\text { Groups of Interests }\end{array}$ & & & & & & & & \\
\hline $\begin{array}{l}\text { Professionals } \\
\text { involved in } \\
\text { territorial Planning } \\
\text { activities }\end{array}$ & & & & & & & & \\
\hline $\begin{array}{l}\text { RESEARCHERS } \\
\text { AND SCHOLARS } \\
\text { (Triggering Actor) }\end{array}$ & $\mathrm{x}$ & & & $\mathrm{x}$ & & & & \\
\hline $\begin{array}{l}\text { Press and } \\
\text { Journalists. }\end{array}$ & & & & & & & & \\
\hline
\end{tabular}

This Concept Matrix, once filled in detail with all the expected Effects of eParticipation, could also be used as a basis for eParticipation evaluation: comparing the a-priori matrix, filled with a description of expected Effects, with an a-posteriori matrix, filled with a description of actual Effects, could be a very interesting goal for eParticipation research, and could trigger an interesting debate on qualitative and quantitative metrics, and on the study of cause-effect relationships within (e)Participation processes.

\section{Conclusions}

This paper has presented a theory building research, which is qualitative in nature. In such a research approach [22] [23], field research was not meant to theory testing (which is normally quantitative in nature), but to point out theoretical / disciplinary lacks, to propose new frameworks (which will need testing in following phases) and to explore possible methodological innovations.

A single case study, such as the Genoa case, would not be epistemologically sufficient in a quantitative, theory-testing research; but in the context of theory building research, even a single, meaningful case study can provide several hints for theoretic proposals [24]. 
The Genoa case, in particular, being developed in form of Action Research [25], yielded several, practice-founded challenges to existing disciplinary frameworks, and was therefore deemed a good starting point to trigger a theoretical reflection.

With respect to the recognized framework of eParticipation discipline, for which we have referred to Sæbø,, Rose and Skiftenes Flak's seminal work [1], we have proposed a threefold framework, based on widened definitions of the categories of eParticipation Actors and eParticipation Activites, and on a re-organized definition of the category of eParticipation Effects. We seeked to define eParticipation (expected) Effects in a form which may be suitable also for providing a basis for eParticipation evaluation metrics.

We do not expect the proposed Framework to be considered exhaustive. The lists of eParticipation Actors, Activities and Effects will be certainly improved if compared and contrasted with many other case studies, in the context of eParticipation research community. When the theory building efforts yield a more experienced framework, it should undergo several theory-testing research processes. Then, and only then, could the eParticipation Framework be presented as sound.

It is the hope of present study's authors that this work will elicit further discussion and research within the eParticipation research community. In particular, for limited length of the paper, the key research streams focusing on eParticipation enabling (contextual) factors and on eParticipation evaluation metrics have been only mentioned here. However, it is recognized that these issues are fundamental in establishing the disciplinary field, and, therefore, should be included in the framework. This task will be the subject of a future research.

\section{References}

1. Sæbø, Ø., Rose, J., Skiftenes Flak, L.: The shape of eParticipation: Characterizing an emerging research area. Government Information Quarterly 25(3), 400-428 (2008)

2. Grönlund, Ä., Horan, T.: Introducing e-GOV: History, definitions and issues. Communications of the AIS 15, 713-729 (2005)

3. Macintosh, A.: Characterizing e-participation in policy-making. In: Proceedings of the 37th Annual Hawaii International Conference on System Sciences. Computer Society Press (2004)

4. Coleman, S.: Personal communication, Demo-net Web-site (2007), http: / /www. demo-net.org

5. Svensson, B., Vensson, B., Flagestad, A.: A governance perspective on destination development - Exploring partnerships, clusters and innovations systems. Tourism Review 60(2), 32-37 (2005)

6. Go, F., Govers, R.: Integrated quality management for tourist destinations: A European perspective on achieving competitiveness. Tourism Management 21(1), 79-88 (2000)

7. Go, F.M., Lee, R.M., Russo, A.P.: E-heritage in the globalizing society: enabling crosscultural engagement through ICT. Information Technology and Tourism 6(1), 55-68 (2003)

8. Innes, J.E., Booher, D.E.: Consensus building and complex adaptative systems. A framework for evaluating collaborative planning. American Planning Association Journal 65(4), 412-423 (1999)

9. Sigala, M., Leslie, D.: International Cultural Tourism: Management Implications and Cases. Elsevier Butterworth-Heinemann, Oxford (2005) 
10. Ciborra, C., Lanzara, G.F.: The transaction costs analysis of the customer-supplier relationships in product development. In: Baskin, A.B., Kovacs, G., Jacucci, G.K. (eds.) Cooperative Knowledge Processing for Engineering Design. Kluwer, Norwell (1999)

11. Bahaire, T., Elliott-White, M.: Community Participation in Tourism Planning and Development in the Historic City of York, England. Current Issues in Tourism 2(2-3), 243-276 (1999)

12. Yuksel, F.: Perceived Clientelism: Effects On Residents' Evaluation of Municipal Services and Their Intentions for Participation in Tourism Development Projects. Journal of Hospitality and Tourism Research 32(2), 187-208 (2008)

13. Paskaleva-Shapira, K., Azorin, J.A., Chiabai, A.: Enhancing digital access to local heritage by e-governance: innovations in theory and practice from Genoa, Italy. Innovation: The European Journal of Social Science Research, 1469-8412 21(4), 389-405 (2008)

14. Mitsche, N., Bauernfeind, U., Lombardi, P., Ciaffi, D., Guida, A., Paskaleva-Shapira, K., Besson, E.: ISAAC-Deliverable 1.1 Report on current digitisation and cultural interpretation in the cities of Amsterdam, Leipzig and Genoa, 28/02/07 (2007)

15. Chiabai, A., Lombardi, P., Chiarullo, L., Rocca, L., Paskaleva-Shapira, K., Brancia, A.: An e-Governance System for Managing Cultural Heritage in Urban Tourist Destinations: The Case of Genoa. In: Cunningham, P., Cunningham, M. (eds.) Collaboration and the Knowledge Economy: Issues, Applications, Case Studies. IOS Press, Amsterdam (2008)

16. Koch, A.: Cyber citizen or cyborg citizen: Baudrillard, political agency, and the commons in virtual politics. Journal of Mass Media Ethics 20(2/3), 159-175 (2005)

17. Jensen, J.L.: Virtual democratic dialogue? Bringing together citizens and politicians. The International Journal of Government and Democracy in the Information Age 8(1/2), 29-47 (2003)

18. Chang, W.Y.: Online civic participation, and political empowerment: Online media and public opinion formation in Korea. Media, Culture and Society 27(6), 925-935 (2005)

19. Albrecht, S.: Whose voice is heard in online deliberation? A study of participation and representation in political debates on the Internet. Information, Communication and Society 9(1), 62-82 (2006)

20. Dahlberg, L.: The Internet and democratic discourse: Exploring the prospects of online deliberative forums extending the public sphere. Information, Communication and Society 4(4), 615-633 (2001)

21. Schneider, S.M.: Creating a democratic public sphere through political discussion. A case study of abortion conversation on the Internet. Social Science Computer Review 14(4), 373-393 (1996)

22. Järvinen, P.: On Research Methods. Opinpaya Oy, Tampere (1999)

23. Eisenhardt, K.M.: Building Theories from Case Study Research. Academy of Management Review 14(4), 532-550 (1989)

24. Yin, R.K.: Case Study research: Design and Methods. Sage Publ., Beverly Hills (1989)

25. Hult, M., Lennung, S.Å.: Towards a definition of Action research: a note and bibliography. Journal of management Syudies 17, 241-250 (1980)

26. Dematteis, G., Governa, F.: Territorialità, sviluppo locale, sostenibilità: il modello Slot, Franco Angeli, Milano (2005) 